\title{
Thoracoscope combined with internal support system of chest wall in open reduction and internal fixation for multiple rib fractures
}

\author{
HONGGANG XIA ${ }^{1 *}$, PENGZHI ZHU ${ }^{1 *}$, JING LI $^{2}$, DEQING ZHU ${ }^{1}$, ZHONGYI SUN $^{1}$, \\ LIMIN DENG $^{1}$, YONGMIN ZHANG ${ }^{1}$ and DONGBIN WANG ${ }^{1}$ \\ ${ }^{1}$ Department of Cardiothoracic Surgery, Tianjin Hospital, Tianjin 300211; \\ ${ }^{2}$ Department of Nursing, Tianjin Medical College, Tianjin 300222, P.R. China
}

Received March 13, 2018; Accepted August 29, 2018

DOI: $10.3892 /$ etm.2018.6817

\begin{abstract}
This study aimed to investigate the feasibility of applying thoracoscope combined with internal support system of chest wall (ISSW) in minimally invasive internal fixation for rib fracture on patients with multiple rib fractures. A total of 84 patients undergoing open reduction and internal fixation for rib fracture from January 2017 to December 2017 in the Department of Cardiothoracic Surgery, Tianjin Hospital were selected into the study, and retrospective analyses were carried out. The clinical data, pain score, operating time, intraoperative blood loss, indwelling time of thoracic tube, total drainage volume of thoracic tube for 3 days after operation, indwelling time of wound drainage tube, total drainage volume of wound drainage tube, length of stay, hospitalization costs, postoperative complications, $\mathrm{C}$-reactive protein (CRP) and pulmonary function of patients in the groups were compared. The patients were followed up for prognosis for 2-4 months via re-examination, and chest numbness at 1 month after operation was recorded. Compared with that $(145.27 \pm 18.80 \mathrm{~min})$ in the traditional group, the operating time in the minimally invasive group $(112.20 \pm 21.40 \mathrm{~min})$ was shorter $(\mathrm{p}<0.05)$. The total drainage volume of wound drainage tube was $145.75 \pm 61.03 \mathrm{ml}$ in the minimally invasive group and $248.91 \pm 93.95 \mathrm{ml}$ in the traditional group $(\mathrm{p}<0.05)$. In addition, the chest numbness at 1 month after operation (11.8\%) in the minimally invasive group was better than that $(34.00 \%)$ in the traditional group $(\mathrm{p}<0.05)$. Postoperative pain score, CRP and pulmonary function tests were also significantly different between the two
\end{abstract}

Correspondence to: Dr Dongbin Wang, Department of Cardiothoracic Surgery, Tianjin Hospital, 406 Jiefang South Road, Tianjin 300211, P.R. China

E-mail:wf8i16@163.com

*Contributed equally

Key words: multiple rib fractures, minimally invasive internal fixation, thoracoscope, internal support system of chest wall groups $(\mathrm{p}<0.05)$. The results indicated that the application of thoracoscope combined with ISSW in minimally invasive internal fixation for rib fracture can effectively improve the prognosis of patients and reduce the length of stay and adverse reactions, and has high economic benefits, which is worthy of promotion and use in clinical practice.

\section{Introduction}

Chest trauma accounts for approximately $13.5 \%$ of all traumas, and the death directly caused by chest trauma accounts for $20-25 \%$ of the death due to all traumas (1). As a chest trauma, multiple rib fracture, especially fractures of multiple ribs, is easily complicated with hemothorax or pneumothorax, greatly impacting the patient's eupnea, or even causing asphyxiation and other extremely dangerous conditions, so emergency thoracic surgical treatment is needed (2) In recent years, open reduction and internal fixation treatment for multiple rib fracture, especially flail chest rib fracture, has achieved satisfactory results, and there is also a consensus on some surgical indications in the industry at the same time $(3,4)$. Because this operation involves multiple and multisegmental ribs, satisfactory exposure can only be obtained by cutting a larger incision in traditional open reduction and internal fixation surgery for rib fracture. Although video-assisted thoracoscopic surgery has been applied to intrathoracic exploration, hemostasis and other treatment for chest trauma and becomes a necessary technical means in the treatment of chest trauma (3,5-7), its specific application in open reduction and internal fixation for rib fracture has not been reported. This is because osseous thorax and chest wall soft tissues are tightly bound to each other, and some dissociated chest wall soft tissues currently have no conventional internal supporting surgical instruments to provide operational space for surgery. In this study, a self-developed internal support system of chest wall (ISSW) capable of distracting the muscular chest wall internally was developed, and the thoracoscope-assisted minimally invasive open reduction and internal fixation for rib fracture was successfully achieved. This surgical method can effectively reduce incision length and damage to chest wall muscles, fully expose surgical field, decrease surgical trauma, save surgical 
manpower, and obtain satisfactory results. This study investigated the application value of thoracoscope-guided minimally invasive open reduction and internal fixation for rib fractures.

\section{Patients and methods}

Clinical data and grouping. A total of 84 patients undergoing open reduction and internal fixation for rib fracture in Tianjin Hospital (Tianjin, China) from January 2017 to December 2017 were selected into the study, and retrospective analyses were performed. These patients were divided into the minimally invasive internal fixation for rib fracture group $(n=34)$ and the traditional incision surgery group $(n=50)$ according to different surgical methods. Inclusion criteria: patients diagnosed with rib fracture by the Imaging Department of Tianjin Hospital before operation, patients with $>4$ fractures (fractured ribs), patients not complicated with spinal, limb and pelvic fractures and abdominal organ injury, patients treated in the Hospital, patients willing to obey with the arrangements of medical staff in the Hospital, and patients with complete medical history. Exclusion criteria: patients with surgical contra indications, patients complicated with other cardiovascular and cerebrovascular diseases, patients complicated with other upper respiratory diseases, patients complicated with other lower gastrointestinal infections, long-term bedridden patients, patients with physical disabilities, patients transferred to another Hospital halfway, and patients receiving treatment from another Hospital during treatment.

The study was approved by the Ethics Committee of Tianjin Hospital. All patients or their guardians signed the informed consent.

Methods. Patients in the minimally invasive group were treated with minimally invasive internal fixation for rib fracture using thoracoscope combined with ISSW. Single-lumen endotracheal intubation was used for general anesthesia. Before operation, fracture locations were marked on the body surface based on apparent chest wall pressure pain point and bone friction feeling in physical examination and presentations on rib three-dimensional computed tomography (CT). Then, a vertical and incline incision was cut in the appropriate midpoint of upper and lower broken ends of rib fractures, closing to the space of chest wall superficial muscles to the greatest extent. The length and number of incision depended on the number and location of rib fractures. Usually, incision length was 6-12 cm. Muscle space was fully used to dissociate chest wall muscles and cut off partial attachment points of chest wall muscles and osseous thoraxes, during which cutting off muscles were avoided as far as possible. ISSW was used to strut part of the dissociated osseous thoraxes and muscular thoraxes up and down, and a space therefrom was a thoracoscopic observation hole to insert into a thoracoscope. After that, space between osseous and muscular thorax was further dissociated to expose the fractured ends of a rib. The upper and lower intercostal muscles of the rib were appropriately stripped off, periostea on both sides of the broken ends of the rib were separated $\sim 2.0 \mathrm{~cm}$, intercostal vascular nerves were anatomical separated and protected, and anatomical reduction of the broken ends of the rib was carried out. According
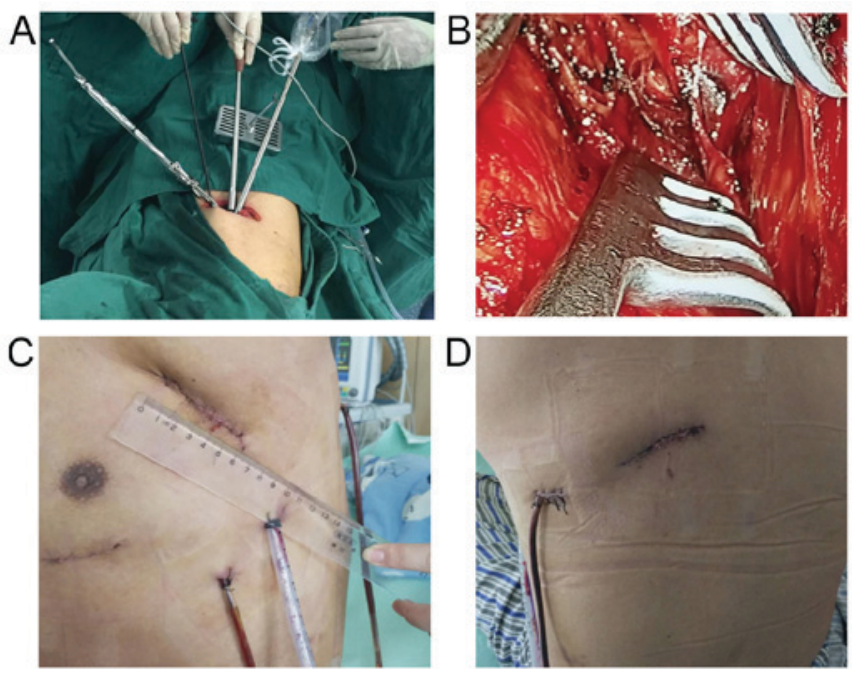

Figure 1. Typical images for a case with rib fracture who received minimally invasive internal fixation using thoracoscope combined with ISSW. (A) A 5-cm incision was made; (B) view under the thoracoscope; (C) anterior incision with the size of $5 \mathrm{~cm}$ after operation; (D) the view of posterior incision after operation. ISSW, internal support system of chest wall.

to the width and shape of the rib where the fracture was located, an appropriate type of memory alloy rib bone plate (ice immersion) was selected, shaped, buckled and pressed on both sides of the broken ends of anatomically reduced fractured rib along the direction of the rib, and fixed using the special rib plate holding clamp in ISSW. Next, sterile saline gauze at $\sim 60^{\circ} \mathrm{C}$ was placed on the surface of the rib plate, to adduct the jaw to hold the rib, completing fracture fixation. After operation, a closed thoracic drainage tube and a wound drainage tube were placed (Fig. 1). Patients in the control group were treated with traditional large incision internal fixation for rib fracture. The clinical data, pain score, operating time, intraoperative blood loss, indwelling time of thoracic tube, total drainage volume of thoracic tube in 3 days after operation, indwelling time of wound drainage tube, total drainage volume of wound drainage tube, length of stay, hospitalization costs, postoperative complications, C-reactive protein (CRP) and pulmonary function of patients in both groups were compared. All patients were followed up for prognosis for 2-4 months via re-examination, and chest numbness at 1 month after operation was recorded.

Observation indexes. i) General indicators included operating time, intraoperative blood loss, indwelling time of thoracic tube, total drainage volume of thoracic tube in 3 days after operation, indwelling time of wound drainage tube, total drainage volume of wound drainage tube, length of stay, hospitalization costs, wound infection and numbness of the affected chest. ii) Rehabilitation indexes covered pain scores at 3 and 7 days before operation and during treatment, and preoperative and postoperative CRP values and pulmonary function in the two groups of patients.

Statistical analysis. Statistical Product and Service Solutions (SPSS) 19.0 software (IBM Corp., Armonk, NY, USA) was used for statistical analysis. Measurement data are expressed as (means $\pm \mathrm{SD}$ ), and t-test was employed. Chi-square 
Table I. Clinical data of the two groups of patients (n, \%).

\begin{tabular}{|c|c|c|c|c|}
\hline Variables & $\begin{array}{l}\text { Minimally } \\
\text { invasive } \\
\text { group }(n=34)\end{array}$ & $\begin{array}{l}\text { Traditional } \\
\text { group }(n=50)\end{array}$ & $\chi^{2}$ & P-value \\
\hline Sex & & & 1.65 & 0.44 \\
\hline Male & $22(64.7)$ & $36(72.0)$ & & \\
\hline Female & $12(35.3)$ & $14(28.0)$ & & \\
\hline Age (years) & & & 2.36 & 0.32 \\
\hline$<45$ & $26(76.5)$ & $35(70.0)$ & & \\
\hline$\geq 45$ & $8(23.5)$ & $15(30.0)$ & & \\
\hline Smoking & & & 3.17 & 0.28 \\
\hline Yes & $24(70.6)$ & $35(70.0)$ & & \\
\hline No & $10(29.4)$ & $15(30.0)$ & & \\
\hline Drinking & & & 4.24 & 0.16 \\
\hline Yes & $18(52.9)$ & $29(58.0)$ & & \\
\hline No & $16(47.1)$ & $21(42.0)$ & & \\
\hline Exercise habit & & & 3.67 & 0.28 \\
\hline Yes & $14(41.2)$ & $22(44.0)$ & & \\
\hline No & $20(58.8)$ & $28(56.0)$ & & \\
\hline Nationality & & & 2.25 & 0.46 \\
\hline Han & $31(91.2)$ & $48(96.0)$ & & \\
\hline Minority & $3(8.8)$ & $2(4.0)$ & & \\
\hline Place of residence & & & 2.95 & 0.36 \\
\hline City & $18(52.9)$ & $27(54.0)$ & & \\
\hline Countryside & $16(47.1)$ & $23(46.0)$ & & \\
\hline $\begin{array}{l}\text { No. of rib } \\
\text { fractures }\end{array}$ & & & 2.36 & 0.41 \\
\hline$<8$ & $24(70.6)$ & $37(74.0)$ & & \\
\hline$\geq 8$ & $10(29.4)$ & $13(26.0)$ & & \\
\hline Pneumothorax & & & 2.88 & 0.37 \\
\hline Yes & $8(23.5)$ & $10(20.0)$ & & \\
\hline No & $26(76.5)$ & $40(80.0)$ & & \\
\hline $\begin{array}{l}\text { Location of } \\
\text { rib fracture }\end{array}$ & & & 3.34 & 0.25 \\
\hline Unilateral & $28(82.4)$ & $38(76.0)$ & & \\
\hline Bilateral & $6(17.6)$ & $12(24.0)$ & & \\
\hline
\end{tabular}

test was used for enumeration data. $\mathrm{P}<0.05$ indicates that the difference was statistically significant.

\section{Results}

Clinical data. Comparisons of the clinical data of the two groups of patients showed that there were no obvious differences in sex, age, smoking, drinking, exercise habit, nationality, place of residence, number of rib fracture, pneumothorax and location of rib fracture of patients between them ( $p>0.05)$, suggesting that the two groups of patients are comparable (Table I).

Comparison of efficacy. There were statistically significant differences in operating time (145.27 \pm 18.80 vs.
$112.20 \pm 21.40 \mathrm{~min}, \mathrm{p}<0.001)$, intraoperative blood loss $(51.00 \pm 12.66$ vs. $78.87 \pm 24.98 \mathrm{ml}, \mathrm{p}<0.001)$, indwelling time of thoracic tube $(3.48 \pm 0.87$ vs. $4.23 \pm 1.14$ days, $\mathrm{p}=0.003)$, total drainage volume of thoracic tube at first 3 days $(475.15 \pm 137.18$ vs. $553.69 \pm 148.1 \mathrm{ml}, \mathrm{p}=0.019)$, indwelling time of wound drainage tube $(2.24 \pm 0.97$ vs. $3.48 \pm 4.22$ days, $\mathrm{p}<0.001)$, total drainage volume of wound drainage tube $(145.75 \pm 61.03$ vs. $248.91 \pm 93.95 \mathrm{ml}, \mathrm{p}<0.001)$, postoperative length of stay $(5.64 \pm 1.11$ vs. $7.58 \pm 1.15$ days, $\mathrm{p}<0.001)$, total hospitalization costs $[7.52 \pm 0.88$ vs. $8.99 \pm 1.15(\mathrm{x} 10,000)$ yuan, $\mathrm{p}<0.001]$, cases of wound infection [1 (2.94\%) vs. 9 (18.00\%), p=0.044] and cases of chest numbness at 1 month after operation [4 (11.8\%) vs. 17 (34.00\%), p=0.023] between the minimally invasive and traditional groups (Table II).

Rehabilitation indicators. Pain scores at 3 and 7 days after operation in the minimally invasive group were significantly better than those in the traditional group $(\mathrm{p}<0.05)$. CRP at 3 and 7 days after operation was clearly better in the minimally invasive group compared with those in the traditional group $(p<0.05)$. Pulmonary function data at 3 and 7 days after operation in the minimally invasive group were overtly superior to those in the traditional group $(\mathrm{p}<0.05)$ (Table III).

\section{Discussion}

Severe chest trauma complicated with multiple rib fractures often leads to severe pain, softening chest wall and paradoxical respiration, and it, coupled with hypoxemia caused by lung contusion, leads to respiratory failure that needs respirator-assisted respiration, and even threatens life. Therefore, the fundamental purpose for the treatment of chest trauma is to fix the chest wall, relieve pain and prevent and cure chest complications (8). The greater the number of rib fractures is, the worse the patient's quality of life becomes (9-11). Currently, many scholars in China and other countries advocate prompt open reduction and internal fixation in the treatment of multiple rib fracture, especially flail chest (12-14). Open reduction and internal fixation for multiple rib fracture can relieve pain, restore thoracic anatomy and respiratory function, reduce the incidence of pulmonary complications, shorten Intensive Care Unit (ICU) mechanical ventilation time and bed-ridden time, and decrease the use of high-dose analgesics and antibiotics $(15,16)$. In addition, it can indirectly reduce gastrointestinal suppression, decrease the incidence of pulmonary atelectasis and chest infections, and lower death rate by reducing complications (17). Internal fixation for rib fracture can restore thoracic integrity and stability, and eliminate paradoxical respiration and abnormal stimulation on the broken ends of fractures, which is a stably optimal choice in the treatment of rib fracture (18).

Moreover, minimally invasive surgery under ISSW developed by Tianjin Hospital has been perfected in orthopedic surgeries with the rapid development of modern medical science and technology. Therefore, this study screened objects of study strictly based on the inclusion and exclusion criteria, carried out experiments and tests in strict accordance with operating guidelines, seriously and rigorously recorded all data of patients, and adopted advanced statistical software for processing, so as to study the advantages 
Table II. Comparison of general indexes of patients between the two groups.

\begin{tabular}{|c|c|c|c|c|}
\hline Variables & $\begin{array}{l}\text { Minimally invasive } \\
\text { group }(n=34)\end{array}$ & $\begin{array}{c}\text { Traditional } \\
\text { group }(n=50)\end{array}$ & $\chi^{2} / \mathrm{t}$ value & P-value \\
\hline Operating time (min) & $145.27 \pm 18.80$ & $112.20 \pm 21.40$ & 7.222 & 0.001 \\
\hline Intraoperative blood loss (ml) & $51.00 \pm 12.66$ & $51.00 \pm 12.66$ & -5.882 & 0.001 \\
\hline Indwelling time of thoracic tube (days) & $3.48 \pm 0.87$ & $4.23 \pm 1.14$ & -3.122 & 0.003 \\
\hline Total drainage volume of thoracic tube at first 3 days $(\mathrm{ml})$ & $475.15 \pm 137.18$ & $553.69 \pm 148.10$ & -2.397 & 0.019 \\
\hline Postoperative length of stay (days) & $5.64 \pm 1.11$ & $7.58 \pm 1.15$ & 7.549 & 0.001 \\
\hline Total hospitalization costs (x10,000 yuan) & $7.52 \pm 0.88$ & $8.99 \pm 1.15$ & -6.147 & 0.001 \\
\hline Indwelling time of wound drainage tube (days) & $2.24 \pm 0.97$ & $3.48 \pm 4.22$ & -5.62 & 0.001 \\
\hline Total drainage volume of wound drainage tube $(\mathrm{ml})$ & $145.75 \pm 61.03$ & $248.91 \pm 93.95$ & -5.521 & 0.001 \\
\hline Cases of wound infection & $1(2.94 \%)$ & $9(18.00 \%)$ & 4.37 & 0.044 \\
\hline Cases of chest numbness at 1 month after operation & $4(11.8 \%)$ & $17(34.0 \%)$ & 5.336 & 0.023 \\
\hline
\end{tabular}

Table III. Comparison of rehabilitation indicators of patients between the two groups.

\begin{tabular}{lcrr}
\hline Variables & $\begin{array}{c}\text { Minimally invasive } \\
\text { group }(\mathrm{n}=34)\end{array}$ & $\begin{array}{c}\text { Traditional } \\
\text { group }(\mathrm{n}=50)\end{array}$ & $\chi^{2 / \mathrm{t} \text { value }}$ \\
\hline Pain score & & & -1.088 \\
Before operation & $6.32 \pm 1.43$ & $6.62 \pm 1.07$ & 7.225 \\
3 days after operation & $57.52 \pm 8.92$ & $86.74 \pm 7.54$ & 7.448 \\
7 days after operation & $36.75 \pm 7.33$ & $58.53 \pm 6.78$ & 0.280 \\
MV (l) & & & 0.002 \\
Before operation & $64.56 \pm 5.27$ & $62.77 \pm 4.89$ & 0.135 \\
3 days after operation & $91.63 \pm 7.54$ & $86.04 \pm 9.69$ & 2.756 \\
7 days after operation & $116.12 \pm 17.39$ & $107.68 \pm 5.40$ & 3.062 \\
FEV1 (\%) & & & 0.007 \\
Before operation & $1.57 \pm 0.36$ & $1.49 \pm 0.33$ & 0.003 \\
3 days after operation & $57.90 \pm 6.19$ & $49.68 \pm 5.67$ & 6.083 \\
7 days after operation & $59.66 \pm 6.09$ & $55.95 \pm 5.11$ & -3.971 \\
CRP (mg/l) & & & 0.278 \\
Before operation & $12.55 \pm 3.27$ & $13.47 \pm 4.08$ & 0.001 \\
3 days after operation & $43.51 \pm 8.28$ & $58.22 \pm 6.07$ & 0.001 \\
7 days after operation & $39.42 \pm 8.64$ & $46.51 \pm 7.10$ & -9.054 \\
\hline
\end{tabular}

MV, minute ventilation; FEV1, forced expiratory volume in $1 \mathrm{sec}$; CRP, C-reactive protein.

of using laparoscope combined with ISSW in the minimally invasive open reduction and internal fixation compared with the traditional large incision surgery, providing a reference and guidance for future clinical treatment of patients with multiple rib fractures.

The results of this study showed that compared with the traditional open reduction and internal fixation, the minimally invasive open reduction and internal fixation for multiple rib fracture using thoracoscope combined with ISSW not only had less damage to patients, but also had a significantly better effect. Based on analyses, this is because the traditional large incision rib fracture open reduction and internal fixation needs to cut off partial chest wall muscles and nerves (long thoracic and thoracodorsal nerve) during operation, damaging some blood vessels below incisions, thus resulting in a higher incision infection rate and postoperative dysfunction: limited upper limb, shoulder and back function, long-term numbness of affected chest. However, open reduction and internal fixation for multiple rib fracture using thoracoscope combined with ISSM is a surgical method based on ISSM, which, compared to conventional surgery, can provide good lighting, comprehensively probe the tissues and structures around the broken ends of fractures in an intuitive and clear manner, determine the specific location, number and severity of fractures, effectively prevent the injury to intercostal vascular nerves, and reduce postoperative intrathoracic bleeding and effusion. At the same time, it does not cut off the chest wall muscles and nerves and can significantly reduce postoperative 
complications. It can be used for surgical opening on anterior, posterior and lateral ribs, because ISSW is able to go deep into the wound and can be opened internally. The width of the front of the lower supporting plate is less than that of the back, so a better surgical incision shape can be obtained. Moreover, ISSW can also support internally when there is a small opening in an outside incision, which is convenient for surgery and avoids contusion of outside muscles of the incision at the same time, so as to realize the minimally invasive surgery.

There were still shortcomings in the comparison of efficacy in the treatment of patients with rib fracture between traditional incision surgery and minimally invasive surgery using thoracoscope combined with ISSW. For example, all study participants were of the same race due to limited experimental conditions and small research object base, so there may be differences in different ethnic groups. In addition, the subsequent follow-up time for patients was short, so it was unable to evaluate the long-term efficacy of the two surgical methods, which will be constantly improved and perfected in future experiments.

In conclusion, application of thoracoscope combined with ISSW in minimally invasive internal fixation for rib fracture can effectively improve the prognosis of patients and reduce the length of stay and adverse reactions, and has high economic benefits, which is worthy of popularization and application in clinical practice.

\section{Acknowledgements}

Not applicable.

\section{Funding}

No funding was received.

\section{Availability of data and materials}

The datasets used and/or analyzed during the present study are available from the corresponding author on reasonable request.

\section{Authors' contributions}

DW conceived and designed the study. JL, DZ, ZS, LD and YZ were responsible for the collection and analysis of the data. HX and PZ interpreted the data and drafted the manuscript. DW, HX and PZ revised the manuscript critically for important intellectual content. All authors read and approved the final manuscript.

\section{Ethics approval and consent to participate}

The study was approved by the Ethics Committee of Tianjin Hospital (Tianjin, China). Signed informed consents were obtained from the patients or their guardians.

\section{Competing interests}

The authors declare that they have no competing interests.

\section{References}

1. Liu CP, Gao JM, Hu P, Li CH, He P, Wang XL, Xiao X and Zhao XJ: Use of bronchofiberscopy in management of severe thoracic trauma. Chin J Traumatol 16: 195-198, 2013.

2. Brasel KJ, Moore EE, Albrecht RA, deMoya M, Schreiber M, Karmy-Jones R, Rowell S, Namias N, Cohen M, Shatz DV, et al: Western Trauma Association critical decisions in trauma: Management of rib fractures. J Trauma Acute Care Surg 82: 200-203, 2017.

3. Leinicke JA, Elmore L, Freeman BD and Colditz GA: Operative management of rib fractures in the setting of flail chest: A systematic review and meta-analysis. Ann Surg 258: 914-921, 2013.

4. Bemelman M, de Kruijf MW, van Baal M and Leenen L: Rib fractures: To fix or not to fix? An evidence-based algorithm. Korean J Thorac Cardiovasc Surg 50: 229-234, 2017.

5. Wang X, Wang L, Zhang H, Li K and Gong X: Feasibility and application of single-hole video-assisted thoracoscope in pulmonary peripheral tumors. Oncol Lett 12: 4957-4960, 2016.

6. Ben-Nun A, Orlovsky M and Best LA: Video-assisted thoracoscopic surgery in the treatment of chest trauma: Long-term benefit. Ann Thorac Surg 83: 383-387, 2007.

7. Milanchi S, Makey I, McKenna R and Margulies DR: Video-assisted thoracoscopic surgery in the management of penetrating and blunt thoracic trauma. J Minim Access Surg 5: 63-66, 2009.

8. Pieracci FM, Majercik S, Ali-Osman F, Ang D, Doben A, Edwards JG, French B, Gasparri M, Marasco S, Minshall C, et al: Consensus statement: Surgical stabilization of rib fractures rib fracture colloquium clinical practice guidelines. Injury 48: 307-321, 2017.

9. Marasco S, Lee G, Summerhayes R, Fitzgerald M and Bailey M: Quality of life after major trauma with multiple rib fractures. Injury 46: 61-65, 2015.

10. Gordy S, Fabricant L, Ham B, Mullins R and Mayberry J: The contribution of rib fractures to chronic pain and disability. Am J Surg 207: 659-663, 2014.

11. Shulzhenko NO, Zens TJ, Beems MV, Jung HS, O'Rourke AP, Liepert AE, Scarborough JE and Agarwal SK: Number of rib fractures thresholds independently predict worse outcomes in older patients with blunt trauma. Surgery 161: 1083-1089, 2017.

12. Slobogean GP, MacPherson CA, Sun T, Pelletier ME and Hameed SM: Surgical fixation vs non-operative management of flail chest: A meta-analysis. J Am Coll Surg 216: 302-311, 2013.

13. Pieracci FM, Rodil M, Stovall RT, Johnson JL, Biffl WL, Mauffrey C, Moore EE and Jurkovich GJ: Surgical stabilization of severe rib fractures. J Trauma Acute Care Surg 78: 883-887, 2015.

14. Marasco SF, Davies AR, Cooper J, Varma D, Bennett V, Nevill R, Lee G, Bailey M and Fitzgerald M: Prospective randomized controlled trial of operative rib fixation in traumatic flail chest. J Am Coll Surg 216: 924-932, 2013.

15. Wada $T$, Yasunaga $H$, Inokuchi $R$, Matsui $H$, Matsubara $T$, Ueda Y, Gunshin M, Ishii T, Doi K, Kitsuta Y, et al: Effectiveness of surgical rib fixation on prolonged mechanical ventilation in patients with traumatic rib fractures: A propensity score-matched analysis. J Crit Care 30: 1227-1231, 2015.

16. Doben AR, Eriksson EA, Denlinger CE, Leon SM, Couillard DJ, Fakhry SM and Minshall CT: Surgical rib fixation for flail chest deformity improves liberation from mechanical ventilation. J Crit Care 29: 139-143, 2014.

17. Fowler TT, Taylor BC, Bellino MJ and Althausen PL: Surgical treatment of flail chest and rib fractures. J Am Acad Orthop Surg 22: 751-760, 2014.

18. Caragounis EC, Fagevik Olsén M, Pazooki D and Granhed H: Surgical treatment of multiple rib fractures and flail chest in trauma: A one-year follow-up study. World J Emerg Surg 11: 27, 2016.

\section{Patient consent for publication}

Not applicable. 